\title{
Fathi Alshare $^{a}$, Nader Mohammad Aljawarneh ${ }^{a^{*}}$, Khaled Abdel kader Alomaria ${ }^{\text {a }}$ Ziyad Saleh Alomaria $^{a}$, Rokaya Albdareen ${ }^{a}$, Ali Awad Alwagfi ${ }^{a}$ and Ahmad Tawfig Alradaideha
}

${ }^{a}$ Business Management, Jadara University, Jordan

\begin{tabular}{l}
\hline C H R O N I C L E \\
\hline Article history: \\
Received: February 16, 2020 \\
Received in revised format: \\
March 272020 \\
Accepted: March 29, 2020 \\
Available online: \\
March 31, 2020 \\
\hline Keywords: \\
Quality \\
Income \\
Price \\
Educational Culture \\
Commercial Brand \\
\hline
\end{tabular}

\section{A B S T R A C T}

\begin{abstract}
The study aimed to examine the brand which is among the main dimensions for making the final purchasing decision among Jordanian consumers when selecting a cellular device which is an index for them and when purchasing in particular. Within this frame, the study aimed to investigate the factors influencing purchasing decision of Jordanian consumers when selecting the brand of cellular devices. The study followed the analytic descriptive approach in data collection where a questionnaire was distributed on a random sample of 240 participants from the study population. The study concluded that there was a positive relationship between the quality of cellular devices and the selection of brand and this relationship was attributed to the variables of gender, age, and educational culture. In light of the results revealed, the study recommended the producers of cellular devices of the various brands to offer high quality products with appropriate prices that take into accounts the purchasing power for consumers based on the targeted markets.
\end{abstract}

(C) 2020 by the authors; licensee Growing Science, Canada

\section{Introduction}

Brand is one of the main tangible dimensions for a product and one of its basic components as by which products are distinguished. It also contributes to easily identify products by consumers as well as it is a legal way to protect products from imitation by competitors (Aljawarneh \& Atan, 2018). Consumer's final purchasing decision is influenced by a group of factors when selecting a commercial brand as income, the main indicator for consumer's selection for brands plays a specific role in consumption spending and have a relationship with the selection of brands consumers to purchase (Aljawarneh \& Al-Omari, 2018). The nature and mechanism of consumption among individuals are affected by several variables among which is the income which defines the direction an individual may approach to encourage industrial company's manufactory to work on producing cellular devices that meet the consumer's income and requirements and his/her purchasing abilities (Al-Omari, et al., 2020). Therefore, it is important for commercial brands to identify products' qualities (Al-Omari et al., 2018). By this brand, the importance of a product is realized and the effect of consumer's income is determined based on selection of brands (Al-Jawarneh, 2016). Studies indicate that the market of phones is the largest competitive industry in the Arab world according to the cellular competition sharpness index issued by the Arab Advisors Group, (2017) and the Jordan came first with a level of $78.1 \%$ at the Arab level. Consumers always seek to fulfill their needs and desires, and the nature of individual's recognition based on his/her wishes. Obiedat and Cao (2008) indicate that the youth select cellular products characterized by modernity and attractive appearance while older people go for mobile devices that only meet their needs. This study comes to identify the effect of income and other variables on consumer's selection for brand which in turn encouraged the researcher to raise the question about whether there is any relationship between the studies on influencing factors and the commercial brands of cellular devices in the Jordanian market. This study also is a justification for identifying that consumer's income and other related variables are main determinants for purchasing luxury goods as well as the brand selected by the consumer. The * Corresponding author.

E-mail address: n.jawarneh@jadara.edu.jo (N. M. Aljawarneh) 
importance of this study lies in determining how an individual makes the purchasing decision as a consumer for cellular devices within the various commercial brands offered in markets and the extent to which income and other variables allow to select among the commercial brand. Obiedat and Cao (2008) identified consumer's satisfaction about the commercial brands of cellular phones offered in markets and identified the relationship with other factors like culture, age and gender when selecting the commercial brand. The Jordanian market is characterized by the sharp competition among cellular communication companies due to the increased need for it and the increased demand on these various brand devices but the consumer's income and other factors represent obstacles for these companies and for famous commercial brands such as Nokia, Samsung, IPhone, and Huawei in particular (Al-Da'abseh et al., 2018; Mahafzah et al., 2020).

\section{Literature Review}

\subsection{Income, price, quality, age, culture \& gender}

Previous studies indicate that the factors that influence the purchasing decision of the final consumer are multiple and each of these factors has a different impact from others depending on its quality and extent of its impact (Al-Da'abseh et al., 2018). Some of the factors related to the famous brand are related to the quality of the commodity, some are associated with advertising and some of which are in line with the luxury products, but the basis of the selection process is associated with consumer behavior. This behavior determines the attractiveness of the consumer to the commodity and this study was conducted in order to investigate the consumers' view since they are the only ones who determine the extent of the impact of these factors to persuade them to accept the commodity. The following are the most important of these factors: Price means the monetary or in-kind value paid by the buyer in exchange for obtaining the good or service. Each institution has financial, production and distribution goals that it seeks to achieve by gaining the largest market share (Alwagfi et al., 2020). These goals are in line with the general goal of the existence of the institution, it should be mentioned that the pricing decisions made by the institution affect those goals in one way or another, but the management of the institution always try to achieve certain goals through pricing decisions. The price affects the consumer's perception of the commodity and it is used to distinguish between the similar commodity classes. This means that consumers are equated with the high price and the selected quality of goods. Some of them use the price as an evidence of the quality of the commodity, even if their feelings indicate that there is no relationship between price and quality (Al-Mansour, 2006).

Culture of a society is defined as a set of cumulative and evolving values, ideas, attitudes and symbols with the development of the nation that define the behavioral patterns of its members, and distinguish it from other nations, in addition to the material output that it reflects and any other meaningful symbols that will help members of the community understand each other and the interpretation and evaluation of the behavior within the community (Al-Mansour, 2006). Culture consists of two elements, the first is moral and the second is material. For the moral one, it includes values, ideas, customs, traditions and religious and non-religious beliefs that prevail in society and for the material one, it includes the material output of the members of society, cellular devices, computers, televisions, cars, and others. Culture includes two types: a general culture and subculture. From the above stated, cultures have a great importance in setting policies and marketing and promotional strategies for many goods and services, and also on the basis of which the market can be divided and be acknowledged of the needs and desires of consumers.

Consumer behavior is a set of behaviors for individuals that are directly related to obtaining and using goods and services, including decisions that define these behaviors and expected to satisfy their desires or needs. Based on the above stated, it can be said that business organizations are working to adopt their marketing plans for the commodity as it must begin with the consumer because satisfying the consumer and satisfying his/her desires and needs are the justification for the presence of marketing the peoplr who have a responsibility to know everything related to potential consumers and the goods that they are marketing (Alwagfi et al., 2020). There are two types of consumers: the first is the final consumer and the second is the industrial consumer. Here we are looking for the final consumer who searches for cellular devices. According to Al-Da'abseh et al. (2018), consumers are different in their purchasing behaviors, some may search to provide what is beneficial for them, while others work on satisfying their needs, therefore individuals are different in their goals, hence understanding and analyzing the driving motives for the behavior of individuals' buying are important as understanding the psychology and characteristics of targeted consumers in order to predict their behavioral, purchasing and consuming patterns which lead to understanding their needs and then working on satisfying those needs and desires. Purchasing depends on certain categories of consumers and the first category is the innovative category with specific purchasing characteristics as innovative consumers tend to show less loyalty to the brand with a great willingness to buy large quantities of new merchandise brands of cellular products. Alshare et al. (2019) it is known that it is not possible to easily identify the motives of individuals, since individuals fulfill their needs in different ways, for example: the elderly group has different goals and motives, while the needs and motivations of the youth category differ.

\subsection{The Brand}

The identification of the brand is among the basic decisions related to the type of device and the distinctive brand of that device, and consumers rely a lot on the distinctive brand and consider it to have an important dimension in the commodity 
concept, given the material and symbolic values this product can add to the consumer, in addition, many consumers use the distinctive brand as a tool to evaluate the device that carries that brand and compares it to other competing devices down to the appropriate consumer choice (Alshare et al., 2019). The brand implies to the consumer a lot of criteria that can be used with the selection process, since it indicates a certain level of specific quality of the good or service, and the social status of the person who can use it, and the decision on the distinctive brand must be taken in light of the convictions of the decision maker that the advantages that the organization can reap from it, and at what cost, and among the most important advantages of the distinctive brand related to the consumer are the followings:

Inferring the quality of the commodity and this explains why the consumer repeats the purchase of the branded good because he/she realizes that he/she will obtain the same level of quality as the good in every commodity (Rokaya \& Al-Ghazzawi, 2018). The distinctive brand, especially the famous one, can reach the consumer's mind, which can become one of the alternatives within the scope of his/her choice, and it is often few in number, since this requires him/her to accumulate experience that enables him/her to evaluate and to judge it before taking it into consideration and entering it into consumerism preferences (Al-Badarin \& Al-Azzeam, 2017). Consumer's income refers to the benefit resulted from capital or work and has two resources: what the individual possesses of money and this is called unearned income and the work or the economic efforts exerted by an individual and this is called earned income. Consumer income is the money that a consumer earns from either work or investment, such as dividends distributed by companies to its shareholders and the gain realized on the sales of an asset, such as a house. When we combine these income sources, it is often referred to as aggregate income. However, life is never that easy, so let's take a closer look at consumer income. According to Kotler and Armstrong (2010) a product's quality has a significant impact towards the product or service performance, thus it is linked to a customer's and satisfaction. It is also vital tool for marketer's product positioning. Today, consumers are demanding high quality goods that save time, energy and often calories. Furthermore, Keegan and Green (2011) believe that the rank that consumers often placed for product quality are as follows; Reliability, Durability, Easy maintenance, Ease of use, a trusted brand name and Low price. The consumer's judgment about the superiority or the degree of excellence of a product is what is referred to as quality of a product. With reference to several past studies on consumer perceptions and their mobile device purchasing behavior, some studies claimed that the buyers of mobile devices strive mainly for product characteristics such as functional, tangible, visible characteristic, or efficient needs. Some people mentioned that the subjective perceptions are in a better position to determine the consumers purchasing choices as compared to the objectives determinants themselves. It is assumed that product characteristic attribute, either functional or technical, are associated with consumers' evaluation of product quality (Alomari, 2020). According to Olshosky (1985), the solid attribute that signal quality of a product differs across product higher level obstructs dimensions of quality which can be generalized to categories of products. As the attribute becomes more abstract, it is common to have more alternatives. In fact, a purchase decision is not the same as an actual purchase. Once consumer chooses a particular brand to purchase, he or she must still implement the decision and make actual purchase (Malkawi, et al., 2018). As consumer makes up his/her minds to purchase a product an additional decision may be needed such as when to buy, where to buy and how much money to spend and even the lapse between the formation of a purchase intention or decision and actual purchase. For a company to maintain a consumer's brand loyalty as they said, it is not easy (Saffar \& Obeidat, 2020). Competitors use many techniques to encourage consumers for non-durable convenience items. It has been observed that, price and quality also influence the consumer decision-making process to purchase or select a product. Court (1999) and Griliches (1997) posit that, the best measure of product quality is price. According to Olson (2000), consumer uses price to measure quality when it is the only available cue. When price is combined with other cues, the evidence is less convincing. Consumer may evaluate quality at the point of consumption. At the point of purchase consumer cannot always evaluate relevant essential attributes of a products. Based on reviewing the early studies and the objectives of the current study and its proposed model, the following hypotheses were formulated:

\section{$\mathrm{H}_{1}$ : There is a relationship between income and brand selection.}

$\mathrm{H}_{2}$ : There is a relationship between quality and brand selection.

$\mathrm{H}_{3}$ : There is a relationship between age, gender, culture on one side and brand selection on the other side.

$\mathrm{H}_{4}$ : There is a relationship between price and brand selection.

\section{Methodology}

The study followed the analytic descriptive approach in collecting the necessary data and information for this study, the population of the study included all citizens purchasing cellular devices with distinctive brands (e.g. Nokia, Samsung, IPhone, and Huawei). The sample of the study was selected using the simple random method from the population of the study and was consisted of 240 participants (Sekaran \& Bougie, 2015). 225 questionnaires were retrieved and 200 of which were valid for analysis which represented $88 \%$ of the total sample size and this percentage is a representative one. The researcher developed a questionnaire to answer the study's questions and to test its hypotheses. The questionnaire consisted of 23 items distributed on all variables of the study, where the items 1-5 measured the first variable of consumer income and its impact on the choice of the brand. As for items 6-10, they measured the second variable, which is the quality of cellular products and 
the choice of the brand and the items 11-15 measured the third variable represented by both age, gender and culture in selecting the brand, as well as items 16-19 measured the fourth variable, the price of the cellular device and its effect on the choice of the brand and finally, the items 20-23 measured the dependent variable of brand. Validity of the tool was verified by subscribing the tool to a jury of specialized and experienced arbitrators and modifications were made based on their opinions. To verify the reliability of the tool, the Cronbach alpha was applied on all items and the Coefficient was 0.75 which is an acceptable value for the purposes of the study application as it is above the accepted 0.70 value indicated by early studies.

\subsection{Results}

This section presents the results of this study which aimed to identify the factors influencing Jordanian consumer's selection for cellular devices brand. The final sample of the study included 200 consumers whom were randomly selected from the population of the study and Fig. 1 illustrates the results of the personal characteristics of the participants.

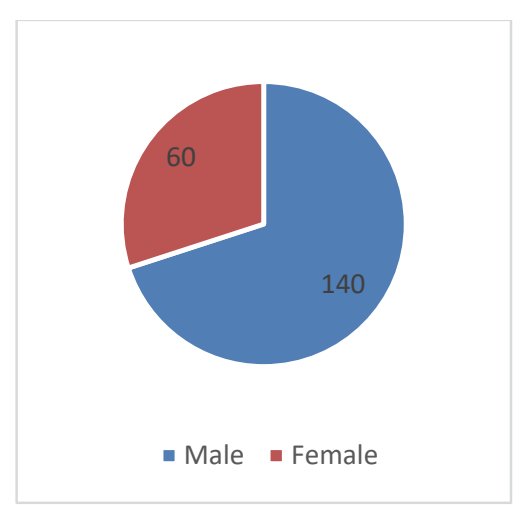

Gender

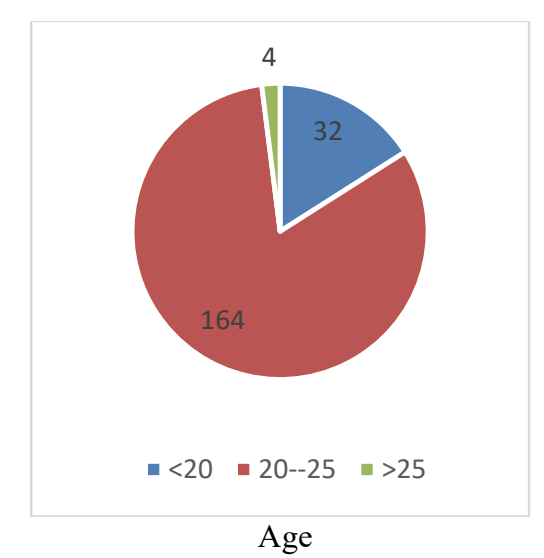

Age

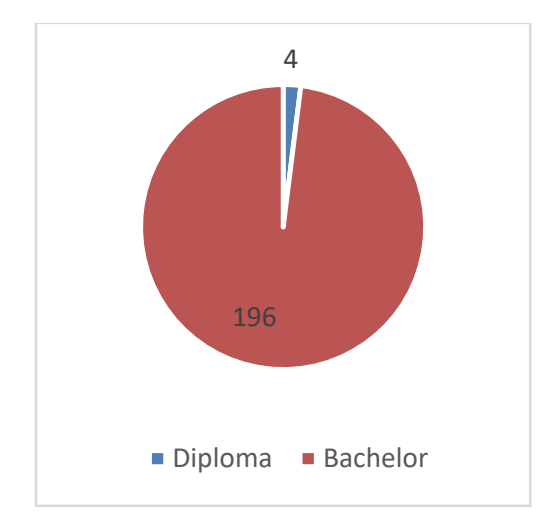

Educational background

Fig. 1. Personal characteristics of the participants

Fig. 1 shows that the percentage of male and female participants were $70 \%$ and $30 \%$, respectively. The highest percentage for participants based on age was $82 \%$ for the age category 20-25 years while the lowest one was $2 \%$ for the age category 26 years and people with older age. The highest percentage for participant's distribution based on the educational level was $98 \%$ for the bachelor degree and the lowest one was $2 \%$ for less than general secondary education. Results related to the study hypotheses to test the hypothesis; the simple regression analysis was applied to study consumer's income in relation to the brand selection as shown in Table 1.

Table 1

Simple regression results for consumer's income on brand selection

\begin{tabular}{cccccccc}
\hline \multicolumn{1}{c}{ Dimple regression results for consumer's income on brand selection } & \multicolumn{1}{c}{ S } & $\beta$ & $\mathrm{T}$ & $\mathrm{R}$ & $\mathrm{R}^{2}$ & $\mathrm{~F}$ & Result \\
\hline income & 0.77 & 5.47 & 0.55 & 0.30 & 30.00 & 0.00 & Accept \\
\hline
\end{tabular}

Table 1 indicates that $\mathrm{R}$ value reached 0.55 which is a statistically significant one and indicates a strong correlation between the consumer's income and brand selection dimensions and R-square value reached 0.30 which is a statistically significant one and interprets the ability of the consumer's income to affect the brand selection. The F test value was 30.00 with a significance of 0.00 which is a statistically significant. For the ratio of the income dimension effect on brand selection which is represented by $\beta$ value, it reached 0.77 with a $T$ value of 5.47 which is statistically significant which indicates a positive and statistically significant effect of the consumer's income dimension on brand selection, thus the hypothesis is accepted.

To test $\mathrm{H}_{2}$, the simple regression analysis was applied to test the products' quality in relation to the brand selection as shown in Table 2.

Table 2

Results of test products' quality on brand selection

\begin{tabular}{cccccccc}
\hline Results of test products' quality on brand selection & $\beta$ & $\mathrm{T}$ & $\mathrm{R}$ & $\mathrm{R}^{2}$ & $\mathrm{~F}$ & Sig & Result \\
\hline Dimension & 0.64 & 8.86 & 0.73 & 0.53 & 78.62 & 0.00 & Accept \\
\hline Products' quality & & & &
\end{tabular}

Table 2 indicates that the value of the correlation coefficient $\mathrm{R}$ reached 0.73 , which is a statistically significant value and indicates the degree of statistically significant correlation between the two dimensions of the quality of products and the brand selection, the value of $\mathrm{R}^{2}$ reached 0.53 which is a statistically significant value that explains the ability of the product quality 
dimension to influence a brand selection. The value of $F$ test was 78.62 with a significance of 0.00 and it is a statistically significant value. For the effect of "quality of cellular products" dimension on the brand selection, which is represented by the value of $\beta$, it reached 0.64 and the value of T was 8.86 which is positive and statistically significant. Thus, the hypothesis is accepted.

To test $\mathrm{H}_{3}$, the simple regression analysis was applied to test the age, gender and culture in relation to the brand selection as shown in Table 3.

Table 3

Results of test age, gender \& culture in brand selection

\begin{tabular}{cccccccc}
\hline Dimension & $\beta$ & $\mathrm{T}$ & $\mathrm{R}$ & $\mathrm{R}^{2}$ & $\mathrm{~F}$ & Sig & Result \\
\hline Age, gender \& culture & 0.77 & 9.37 & 0.75 & 0.56 & 87.95 & 0.00 & Accept \\
\hline
\end{tabular}

Table 4 indicates that $\mathrm{R}$ value reached 0.75 and this is a statistically significant one between Age, gender, culture and brand selection where $\mathrm{R}^{2}$ value was 0.56 which is also a statistically significant and explains the age, gender and culture dimension's ability in affecting the brand selection. The value of $F$ test reached 87.95 with a significance while the ratio of $\beta$ was 0.77 and that of T was 9.37 and these are positive and statistically significant indicating a positive effect for age, gender and culture on brand thus the hypothesis is accepted.

To test $\mathrm{H}_{4}$, the simple regression analysis was applied to test the cellular device price in relation to the brand selection as shown in Table 4.

Table 4

Results of test the price in the brand selection

\begin{tabular}{cccccccc}
\hline Dimension & $\beta$ & $\mathrm{T}$ & $\mathrm{R}$ & $\mathrm{R}^{2}$ & $\mathrm{~F}$ & Sig & Result \\
\hline price & 0.82 & 2.82 & 0.84 & 0.70 & 14.65 & 0.00 & Accept \\
\hline
\end{tabular}

Table 4 indicates that the value of the correlation coefficient $\mathrm{R}$ reached 0.84 , which is a statistically significant value and indicates the degree of statistically significant correlation between the dimension prices on brand selection, the value of $\mathrm{R}^{2}$ reached 0.70 which is a statistically significant value that explains the ability of the price to influence brand selection. The value of the $\mathrm{F}$ test was 14.65. As for the ratio of the impact of price on brand selection, which is represented by the value of $\beta$, it has reached 0.82 and the value of $T$ has reached 2.82 which are positive values and statistically significant and this shows the positive impact and statistically significant one for the price on brand selection, therefore the hypothesis is accepted.

\section{Conclusion}

The results of the study indicated the followings: There is an influential role for income, and the price and technologies found in the cellular device in selecting the brand. This role is highlighted by the popularity of purchasing famous brands. This result was in agreement with the results of Al-Duhaish et al. (2014), Saleh and Al-Khader (2010), Sata (2013) and Karjaluoto et al. (2005), who showed that there was a correlation between income and the increased demand for cellular devices. There is a statistically significant effect on the quality of the product and the brand selection, and this appears through consumer's interest in associating the quality with the brand purchase. This result is inconsistent with some of the results of previous studies such as the Khazaleh study (2015) which focused on reducing taxes as an indicator to increase the demand by the buyer. There is a statistically significant effect of price and brand selection as it is characterized by the fact that the consumers buy branded cellular devices of acceptable prices, which focused on commercials and their impact on purchasing behavior.

\section{Recommendations}

In light of the results of this study, the researcher has the following recommendation: Encouraging the manufacturing of cellular devices of all kinds with good quality and affordable prices for everyone, taking into account the purchasing power of consumers according to the targeted markets preferences. Producer companies must realize that the high price is not an indication of quality as it was previously understood by consumers, and that there are other factors that have contributed to lower prices, such as operating costs, brands, country of origin, and thus leading citizens to be reluctant to purchase cellular devices with higher price. The high, famous brands, and the search for alternatives because consumers are now aware that there are unknown brands that have been competing in terms of quality and price.

\section{Acknowledgement}

The authors would like to thank the anonymous referees for constructive comments on earlier version of this paper. 


\section{References}

Al Khazaleh, A.M. (2015). Factors affecting the decision to purchase hybrid cars in Amman, Jordan. Master Thesis published Zarqa Private University.

Al-Badarin, R. Q., \& Al-Azzeam, A. H. (2017). Job design and its impact on the job strain: Analysing the job as a moderating variable in the private hospitals in Irbid. International Journal of Humanities and Social Science, 7(3), 152-168.

Al-Da'abseh, T.., Aljawarneh, N. \& Shwiyat, Z. (2018). Marketing mix strategies and its impact on organizational performance efficiency in the Jordanian company for investment and supply-Safeway: An empirical study. Invention Journal of Research Technology in Engineering \& Management, 2(2), 14-23.

Al-Duhaish, A., Alshurideh, M., \& Al-Zu'bi, Z. (2014). The impact of the basic reference group usage on the purchasing decision of clothes (A field study of Saudi youth in Riyadh city). Dirasat: Administrative, 41(2), 205-221.

Al-Jawarneh, N. M. S. (2016). Case study: Business management school at the Turkish republic of north Cyprus and how strategic thinking and planning can improve the performance of the organization to maintain stable between competitors. Invention Journal of Research Technology in Engineering \& Management (IJRTEM), 1(5), 64-72.

Aljawarneh, N. M. S., \& Atan, T. (2018). Linking tolerance to workplace incivility, service innovative, knowledge hiding, and job search behavior: The mediating role of employee cynicism. Negotiation and Conflict Management Research, 11(4), 298-320.

Aljawarneh, N., \& Al-Omari, Z. (2018). The role of enterprise resource planning systems ERP in improving customer relationship management CRM: An empirical study of Safeway company of Jordan. International Journal of Business and Management, 13(8), 86-100.

Al-Mansour, K.N. (2006). Consumer behavior: the entrance to advertising.

Alomari, K. (2020). Management bias as a cause of employee weak performance: Case Study at Jadara University. Management Science Letters, 10(8), 1729-1736.

Al-Omari, Z. S., Aljawarneh, N., Davut, S., \& Salah, A. (2018). The Impact of Marketing Mix Elements on Forming Mental Images about Islamic Banks in Jordan: An Empirical Study. OFFICIAL, 12, 54.

Al-Omari, Z., Alomari, K., \& Aljawarneh, N. (2020). The role of empowerment in improving internal process, customer satisfaction, learning and growth. Management Science Letters, 10(4), 841-848.

Alshare, F., Alkhawaldeh, A. M., \& Eneizan, B. M. (2019). Social Media Website's Impact on Moral and Social Behavior of the Students of University. International Journal of Academic Research in Business and Social Sciences, 9(3).

Alwagfi, A. A., Aljawarneh, N. M., \& Alomari, K. A (2020). Work Ethics and Social Responsibility: Actual and Aspiration. Journal of Management Research, 12(1), 26-36.

Karjaluoto, H., Karvonen, J., Kesti, M., Koivumäki, T., Manninen, M., Pakola, J., ... \& Salo, J. (2005). Factors affecting consumer choice of mobile phones: Two studies from Finland. Journal of Euromarketing, 14(3), 59-82.

Keegan, W. J., \& Green, M. C. (2011). Global marketing. (pp. 4-28).

Kotler, P., \& Armstrong, G. (2010). Principles of marketing. Pearson education.

Malkawi, N. M., Al Omari, K., \& Halasa, A. (2018). Intellectual Capital as a Core Competency for Competitive Advantage: A Case Study. Journal of Digital Information Management, 16(4).

Mahafzah, A. G., Aljawarneh, N. M., Alomari, K. A. K., Altahat, S., \& Alomari, Z. S. (2020). Impact of customer relationship management on food and beverage service quality: The mediating role of employees satisfaction. Humanities \& Social Sciences Reviews, 8(2), 222-230.

Obiedat, E. A., \& Cao, L. (2008). Turbo decoder for low-power ultrawideband communication systems. International Journal of Digital Multimedia Broadcasting, 2008.

Rokaya, A. L., \& Al-Ghazzawi, H. (2018). Diversity training and its impact on the employees' organizational commitment: job satisfaction as a moderating variable in the Classic Fashion Apparel Industry company. International Journal of Business and Management, 13(10).

Saffar, N., \& Obeidat, A. (2020). The effect of total quality management practices on employee performance: The moderating role of knowledge sharing. Management Science Letters, 10(1), 77-90.

Sekaran, U., \& Bougie, R. (2016). Research methods for business: A skill building approach. John Wiley \& Sons.

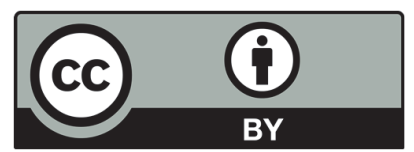

(C) 2020 by the authors; licensee Growing Science, Canada. This is an open access article distributed under the terms and conditions of the Creative Commons Attribution (CC-BY) license (http://creativecommons.org/licenses/by/4.0/). 